\title{
Editorial:
}

\section{Special Volume on Social Work in the Canadian North}

Douglas Durst Douglas Durst, Ph.D. University of Regina, Canada

Editor of JCSW Issue 1, 2012 
As guest editor, I am honoured to have participated in the development of this special volume with my friend and colleague Dr. Siv Oltedal, and Henrik Dvergsdal, University of Nordland, Norway. The history of its creation is quite long and complicated and starts with the launch of the University of the Arctic in June, 2001. The University of the Arctic (UArctic) is a cooperative network of about 130 northern universities, colleges and other related organizations committed to education, research and the promotion of Indigenous and local peoples and sustainable development in the circumpolar North. (www.uarctic.org, 2012). Out of this network, a number of thematic networks have been formed to address specific issues or concerns. In the spring of 2006, colleagues at University of Nordland (formerly Bodo University College) hosted a thematic conference on social work of which I had the great pleasure of participating. From this social work thematic group, faculty and researchers from Russia, Finland, Sweden, Canada and Norway collaborated on a number of projects. Later colleagues from Alaska, Iceland and Greenland joined the group. In 2011, the UArctic thematic network hosted an international conference on social work in the north. The conference was titled Supporting Healthy Communities through Social Work and was held in Reykjavik, Iceland, August 2011 (sorry that you missed it). The conference was well supported by Canadian scholars and from the papers presented at the conference, we worked at developing this special issue with heavy bias from Canada. All of the articles but one explore social work education and practice issues in Canadian Arctic and northern communities.

The special volume begins with an intriguing discussion on the issues facing social work education in the Canadian Arctic. Nuelle Novik calls upon her direct experience as a northern social work educator; she points out that southern cultural values such as individualism often conflict with the northern values that emphasis communitarianism. Other issues include the diltuting of the professional education through temporary training and workshops and transporting culturally inappropriate education through technology.

As part of the opening, Nicole Ives and I present an essay on the history of social work educaton in the Canadian north. Social work education had an emphasis on local capacity building, working with the Indigneous peoples of the Canadian Arctic. It provides an important overview of the peoples and land of the Canadian north. It explores the early years of formalized social work education and efforts to bring it north and indigenize the programs to ensure northern relevancy. The essay is a helpful background to understanding the other papers in this edition and nowhere else is this history documented.

Nicole Ives' paper, Exploring the Intersection of Culture and Education in Nunavik, presents the issues facing Inuit peoples in region known to many Canadians as Arctic Quebec (Nunavik). It is a very unique part of the world that often gets overlooked. Her qualitative research involed 52 interviews with people in these small and isolated communities. Her findings indicated the region is under considerable change with emerging generational gaps on issues of language, culture, and education. The study looks for solutions from education and culture to address issues such as low academic retention and completion by young people.

Glen Schmidt, Dawn Hemingway and Gerard Bellefeuille submitted a paper, Building Healthy Northern Communities Through Strengthening Capacity that examines the 
effects of one-time funding on capacity building program for health and social agencies in the northern regions of British Columbia. Twenty-five communities participated and the researchers followed up 6 years after the funding ended. Most of the projects were terminated and those that continued, used other resources or collaborated with other organizations. They concluded that one-time funded projects offer some short term benefits but little in the long term.

Ralph Bodor and Carol Melnyk-Poliakiwski document a creative graduate program for First Nations (Indigenous People) in Alberta. In Exploring the Unique Features of a First Nations Graduate-Level Social Work Program, they document a one-time cohort of students. The article follows their journey through a unique Master of Social Work Program delivered in their community. All aspects of the program integrated traditional knowledge and ways of learning that challenged Western perspectives of social work. The article presents detailed descriptions of the program and how it progressed with limitations and victories.

In The Role of Social Work in Palliative Care, Nuelle Novik reports on her qualitative study that examined the issues surrounding palliative care with seniors in remote northern settings. She finds that there is an important role in supporting those who are dying and their families but in many regions, the profession of social work is less developed and the formal role of social work is minimal.

I have often said that it is impossible to hide in small communities and Keith Brownlee, Glenn Halverson and Ahlea Chassie tackle the conflicting roles in small community life in their article, Multiple Relationships: Maintaining Professional Identity in Rural Social Work Practice. Community members expect their professionals to be engage and involved in the community both professionally and personally which generate overlapping relationships. Their qualitative study had a sample of more than 12 communities in rural and remote locations in the northern regions of Manitoba and Ontario. The article sheds important light on the isolated community life of professional social workers as they juggle competing and conflicting roles.

Arne Backer Groenningsaeter and Riina Kiik's article breaks from the previous papers that relate to the Canadian North. Although, they did not participate in the UArctic conference, we felt that the article is relevant and timely. They present a study involving 8 focus groups with social workers from Estonia and Norway exploring the relationship between social policy and social work. In Implementing Social Policy - Social Worker's Experience from Estonia and Norway, they find that the workers are more concerned about the issues facing the individual and less than the broader framework of social policy. Regrettably, it seems like a universal theme that social workers are focused on the micro level of practice and have a limited view of their role in developing and implementing social policy.

Well, here is our special edition with its emphasis on social work in the northern and Arctic regions of Canada. As a reader, you can see that much has been done but much still needs to be accomplished. As editors, we hope that this knowledge will build the profession, not just in the Canadian north but the circumpolar north with applications to all Indigenous people and isolated communities around the globe. Truly, the Journal of Comparative Social Work is global. 